Check for updates

Cite this: RSC Adv., 2017, 7, 19257

\title{
Novel terpolymers as viscosity reducing agent for Tahe super heavy oil
}

\author{
Jincheng Mao, (D)* Jiawei Liu, Haibin Wang, Xiaojiang Yang, Zhaoyang Zhang, \\ Bo Yang and Jinzhou Zhao*
}

The four components of extra-heavy oil (saturates, aromatic, resins, asphaltene) were analyzed by chemical separation. The terpolymers with different contents of styrene (S), alkyl chain (MM/DM), and vinyl acetate (V) were designed, synthesized and employed as the viscosity reducers for super heavy oil. Thus, structure and average molecular weight of the oil-soluble terpolymers were measured by Fourier-transform infrared (FTIR) and gel permeation chromatography (GPC), respectively. Comparing with the apparent viscosity of heavy oil in a wide range of shear rates $\left(0.1-200 \mathrm{~s}^{-1}\right.$ ) and temperatures $\left(25-75^{\circ} \mathrm{C}\right)$, it can be seen that optimal efficiency could be achieved to reduce viscosity when the terpolymer has a high percentage of long-chain alkyl. Furthermore, the molar ratio between long-chain alkyl groups and aromatic ring as well as molecular weight of terpolymers play a fundamental role in viscosity reduction of super heavy oil.

Received 12th January 2017

Accepted 26th February 2017

DOI: $10.1039 / \mathrm{c} 7 \mathrm{ra00508c}$

rsc.li/rsc-advances

reservoirs in Northwest China are deeply buried and geological environment is complex. Deep wells will cause energy loss and low productivity. In addition, horizontal well production practice is not suitable for heterogeneous reservoirs. Other common-used approach in China that has been used to reduce viscosity in heavy crude oils will employ blending light oil. ${ }^{10}$ However, such dilution and blending method usually requires a lot of light oil, which must have a convenient source. ${ }^{11,12}$

Another method of reducing the viscosity of heavy oil is to use viscosity reducer chemicals. All chemical additives have a strong selectivity for crude oil. ${ }^{13,14}$ Many chemical polymers have been developed as flow improvers for heavy crude oils, but these compounds of polymers are designed for paraffin, to reduce the pour point, and have moderate to little effect in asphaltenic oils. ${ }^{15}$ The researchers all pay attention to the structure characterization of resin and asphaltene in crude oils. Moreover, the reactivity ratios of the monomers employed in the polymerization are different, and the research show that homogeneous terpolymerizations are obtained under monomer-starved conditions in semi-continuous processes independent of reactivity values. ${ }^{2}$ In recent years, molecular simulation method was introduced to analyses the interactions among resin, asphaltene and synthesized polymer. Therefore, it is highly desirable for the development of the polymer molecules, which are capable of dispersing or breaking aggregates of resins and asphaltene.

\section{Materials and methods}

\section{A. Materials}

Maleic anhydride, stearyl alcohol, styrene (S), vinyl acetate (V), azobisisobutyronitrile (AIBN), benzoylperoxide (BPO), 
p-toluenesulfonic acid, toluene, heptane, methanol and 1dodecanethiol were purchased and used without further purification. Distilled water was used during the experiments. Heavy crude oil was obtained from the Tahe Oilfield (in China's Xinjiang), the properties of which are shown in Table 1.

\section{B. Synthesis and evaluation}

The dioctadecyl maleate (DM) was prepared using maleic anhydride and stearyl alcohol as raw materials in the presence of $p$-toluenesulfonic acid as catalyst, and the reaction was carried out for $3.5 \mathrm{~h}$ at $95{ }^{\circ} \mathrm{C}$. Monostearyl maleate (MM) was also synthesized from maleic anhydride and stearyl alcohol for $5 \mathrm{~h}$ at $140{ }^{\circ} \mathrm{C}$. The mole ratios of DM and MM were 2.1:1 and $1.2: 1$. Random terpolymers with various molar ratios of polymer monomers (DM or MM), S and VA were synthesized via freeradical polymerization in toluene solution under an argon atmosphere, using azobisisobutyronitrile as the initiator (0.8 wt\%) and 1-dodecanethiol as the chain transfer agent at $75{ }^{\circ} \mathrm{C}$. About $4 \mathrm{~h}$ later, the reaction mixture was cooled to room temperature and poured dropwise in cooled methanol with continuous stirring. The precipitate was collected by filtration and dried at $65{ }^{\circ} \mathrm{C}$ for $24 \mathrm{~h}$, appearing as either white viscous liquid or white powder. The structure of the polymer monomers (DM, MM) and copolymer were confirmed by Fourier-transform infrared (FTIR) spectroscopy (BRUKER). The molecular weights of synthesized copolymers (DM-S-V, MM-S-V) were determined by using gel permeation chromatography (GPC; Perkin Elmer Corporation).

\section{Sample preparation}

Heavy crude oil is a black solid at room temperature and the apparent viscosity could not be measured. Firstly, heavy oil was heated in an oven for $2 \mathrm{~h}$ and then blended and stirred with light oil (kerosene, diesel oil) to form a stable homogeneous mixture. To obtain results consistent with accurate rheological properties, the memory of the evaluated untreated crude oil sample and all crude oil used as an additive with viscosity reducer, have to be removed by heating at $50{ }^{\circ} \mathrm{C}$ while stirring. Finally, all samples in the container were maintained at the temperature required for the reaction for a few minutes.

Table 1 Physical characterization of crude oil

\begin{tabular}{lll}
\hline Parameter & Unit & Value \\
\hline Density & $\mathrm{g} \mathrm{cm}^{-3}, 25{ }^{\circ} \mathrm{C}$ & 0.966 \\
API gravity & $60 / 60^{\circ} \mathrm{F}$ & 14.9 \\
Wax content & $\mathrm{wt} \%$ & 1.8 \\
Pour point & ${ }^{\circ} \mathrm{C}$ & 42 \\
Viscosity & $\mathrm{mm}^{2} \mathrm{~s}^{-1}, 50{ }^{\circ} \mathrm{C}$ & 3665 \\
Sediment & $\mathrm{wt} \%$ & 7.05 \\
Saturates & $\mathrm{wt} \%$ & 20.29 \\
Aromatic & $\mathrm{wt} \%$ & 26.12 \\
Resin & $\mathrm{wt} \%$ & 19.03 \\
Asphaltene & $\mathrm{wt} \%$ & 27.51
\end{tabular}

\section{Rheological behavior of crude oil}

Samples of $20 \mathrm{~g}$ of heavy crude oils were dosed with $0.2 \mathrm{~g}$ of a solution of terpolymers. The rheological investigation was carried out using the MCR-302 rheometer (Anton-Paar Physica, made in Austria), equipped with a variety of concentric cylinders. The crude oil was examined under a shear rate range of 1.0-200.0 $\mathrm{s}^{-1}$ at $50{ }^{\circ} \mathrm{C}$. For comparative purposes, untreated crude oil was measured to be used as reference samples.

\section{Results and discussion}

\section{A. Characterizations of viscosity reducer chemicals}

The compositions of the synthesized monomers were characterized by the IR spectrometry. The spectrum of MM is clearly shown in Fig. 1, and an absorption band corresponding to the $\mathrm{OH}$ stretch of the carboxyl group is present at $3522.50 \mathrm{~cm}^{-1}$. The ester group bands resulting from the $\mathrm{C}=\mathrm{O}$ and $\mathrm{C}-\mathrm{O}-\mathrm{C}$ stretching were found at $1728.56 \mathrm{~cm}^{-1}$ and $1222.51 \mathrm{~cm}^{-1}$, respectively, and an absorption band corresponding to the carboxyl group is present at $1706.79 \mathrm{~cm}^{-1}$. The characteristic $\mathrm{C}=\mathrm{C}$ stretching peak appears near $1636.86 \mathrm{~cm}^{-1}$. The spectrum of DM, which contains two long-chain alkanes, is shown in Fig. 2, displaying absorption bands near 2916.60 and 2850.19 $\mathrm{cm}^{-1}$ for methyl and methylene groups, respectively, as well as stretches at 1729.08 and $1222.92 \mathrm{~cm}^{-1}$ for the ester group $(\mathrm{C}=\mathrm{O}$

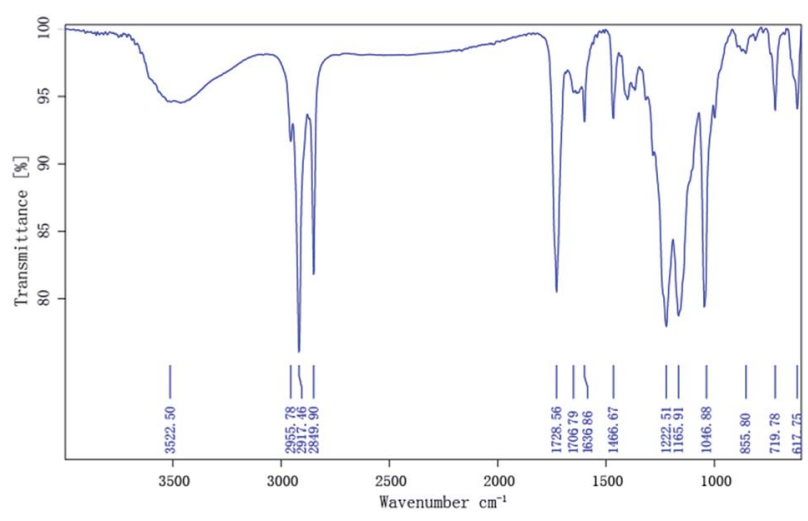

Fig. 1 IR spectrum of MM.

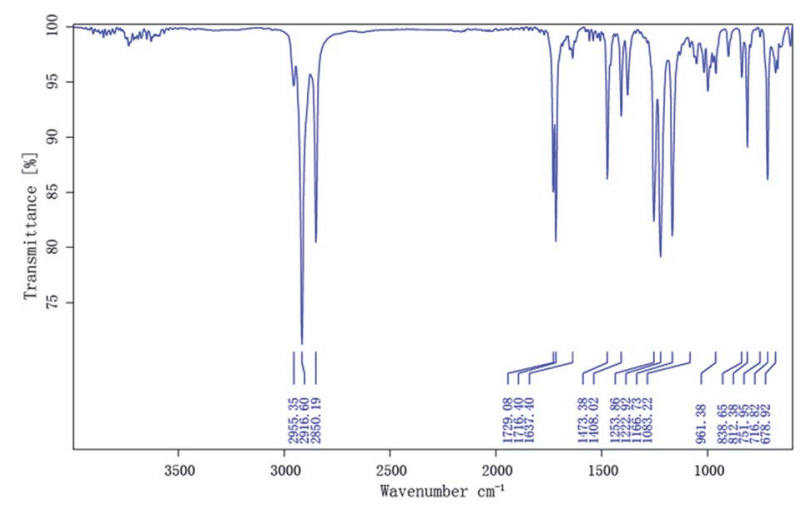

Fig. 2 IR spectrum of DM. 
and $\mathrm{C}-\mathrm{O}-\mathrm{C})$. A characteristic $\mathrm{C}=\mathrm{C}$ stretching band appears near $1637.40 \mathrm{~cm}^{-1}$. The antisymmetric and symmetric peaks of $\mathrm{C}=\mathrm{O}$ in maleic anhydride do not appear near 1850 and 1780 $\mathrm{cm}^{-1}$, and thus the product is proved to be DM.

The free-radical polymerization, widely employed in many modern industrial processes, consists of three stages: initiation, propagation, and termination. The amount of chain-transfer agent (CTA), monomer molar ratio, reaction time can affect the performance of the polymer. The chemical structure of the synthesized compounds is shown in Fig. 3. It is important to mention that the conversion rate of the polymerization reaction is above $80 \%$ and therefore, the monomer mixtures were added in one. ${ }^{8}$

Terpolymers composition were determined by GPC. Table 2 shows the polymer composition (PC), average molecular weights $\left(M_{\mathrm{w}}\right.$ and $\left.M_{\mathrm{n}}\right)$, polydispersity (PD), and degree of polymerization of the terpolymers. The IR spectra of the prepared terpolymers of MM-S-V and DM-S-V are shown in Fig. 4 and 5, respectively. For example, the methyl and methylene absorption bands (2916.84 and $2849.91 \mathrm{~cm}^{-1}$ ), as well as stretches at 1729.51 and $1223.66 \mathrm{~cm}^{-1}$ for the ester group $(\mathrm{C}=\mathrm{O}$ and $\mathrm{C}-\mathrm{O}-$ $\mathrm{C})$, and the strong absorption peak of the benzene ring (1473.33 $\mathrm{cm}^{-1}$ ) appear in Fig. 5, and DM was confirmed.

\section{B. Rheological studies}

The apparent viscosity of the crude oil sample was determined at different shear rates and temperatures, using a Physica MCR302 rheometer. The original rheological properties of Tahe crude oil is shown in Fig. 6 . It is clearly seen that at $50{ }^{\circ} \mathrm{C}$, the apparent viscosity is not constant at different shear rates (shear curve). The changes of viscosities curve at shear rates between 0.1 and $143 \mathrm{~s}^{-1}$ are very small (e.g., from $2.78 \mathrm{~Pa} \mathrm{~s}$ at $0.1 \mathrm{~s}^{-1}$ to

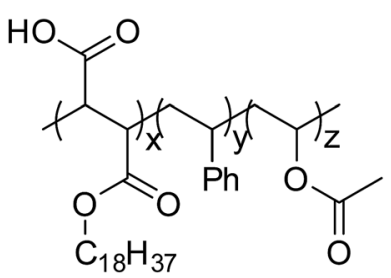

MM-S-V

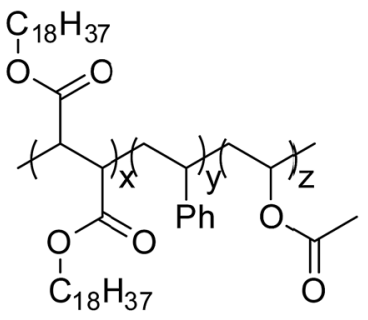

DM-S-V
Fig. 3 Structural representation of terpolymers (MM-S-V and DM$S-V)$.

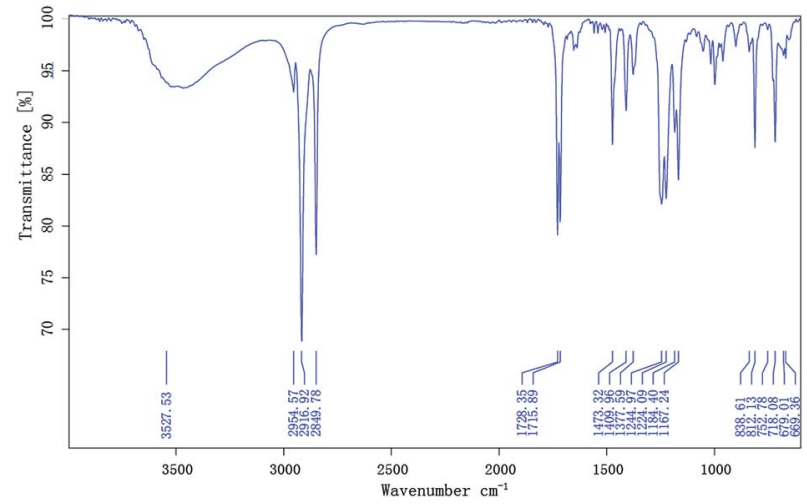

Fig. 4 IR spectrum of MM-S-V.

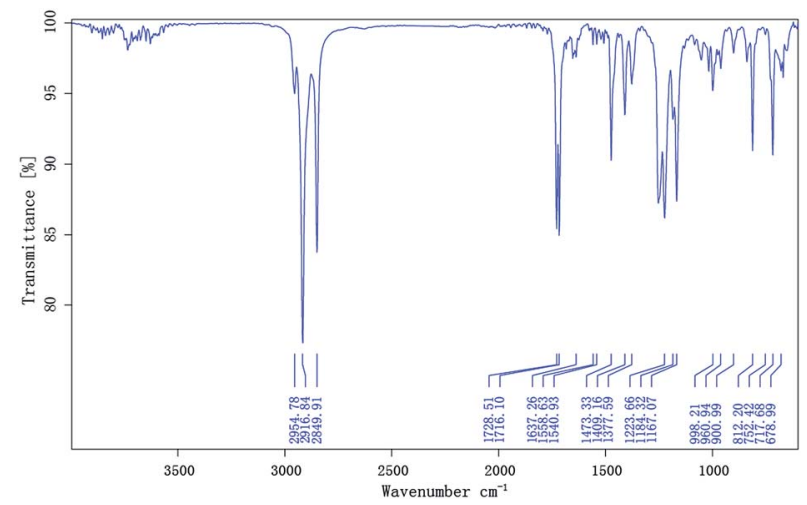

Fig. 5 IR spectrum of DM-S-V.

2.12 Pa s at $143 \mathrm{~s}^{-1}$ ). By increasing the shear rate, the apparent viscosity decreases dramatically. This rheological behavior of the crude oil is "non-Newtonian" fluid (similar to Bingham plastic fluid). ${ }^{16,17}$ It is also obvious that heavy oil is very sensitive to temperature. When the temperature rises by 10 degrees, the viscosity almost became the half (temperature curve in Fig. 9), which is due to the reason that the thermal recovery method is so common in the petroleum sector.

\section{Effect of the molecular weight and molecular composition on viscosity-reducing property}

Fig. 7 shows representative plots of shear rate $(\gamma)$ versus apparent viscosity $(\eta)$ of heavy crude oil containing $1 \mathrm{wt} \%$ of terpolymers at $50{ }^{\circ} \mathrm{C}$. Untreated crude oil and that containing terpolymers showed non-Newtonian fluid properties, and thus

Table 2 Composition and molecular-weight characterization of terpolymers

\begin{tabular}{llllll}
\hline Polymer code & MM (mol\%) & DM (mol\%) & S (mol\%) & VA (mol\%) & $M_{\mathrm{w}}$ \\
\hline $\mathrm{S}_{1}$ & 5.0 & - & 71.5 & 23.5 & 3172 \\
$\mathrm{~S}_{2}$ & 20.0 & - & 60.0 & 20.0 & 2420 \\
$\mathrm{~S}_{3}$ & 20.0 & - & 60.0 & 20.0 & 3315 \\
$\mathrm{~S}_{4}$ & - & 33.5 & 16.5 & 50.0 & 42660 \\
$\mathrm{~S}_{5}$ & - & 50.0 & 12.5 & 37.5 & 4561 \\
\end{tabular}




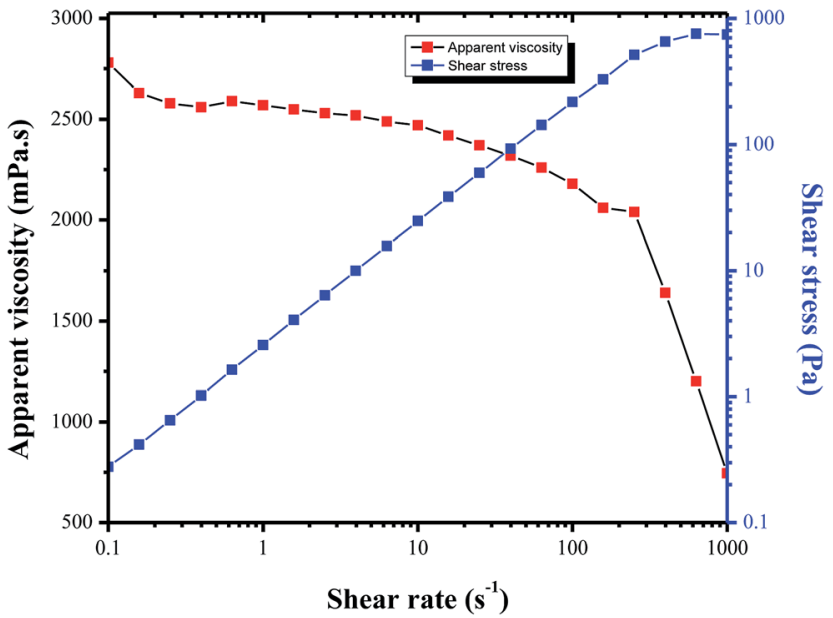

Fig. 6 Rheogram of the heavy oil sample at $50{ }^{\circ} \mathrm{C}$.

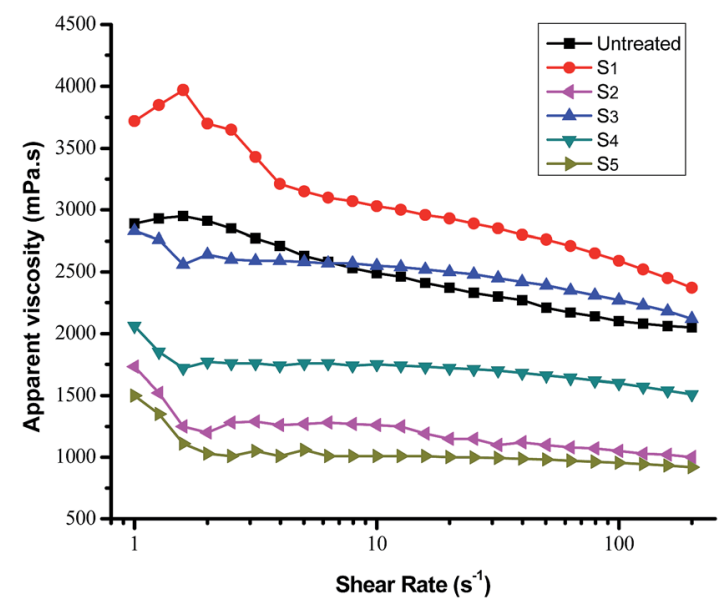

Fig. 7 Apparent viscosity of heavy crude oil containing 1 wt\% of terpolymer solution as a function of the shear rate at $50^{\circ} \mathrm{C}$.

using simple Newtonian behavior to explain flow properties is inaccurate. At a shear rate lower than $2.5 \mathrm{~s}^{-1}$, the apparent viscosity fluctuation is more evident. Shear continued to increase, showing a slow decline trend, as mentioned in the literature. ${ }^{2}$

It can be seen that terpolymers $\mathrm{S}_{2}, \mathrm{~S}_{4}$ and $\mathrm{S}_{5}$ diminish the crude oil apparent viscosity obviously. The efficiency of viscosity reducing chemicals depends upon the average molecular weight, alkane chain length, solubility and intermolecular interactions between polymer and crude oil. The performance of terpolymer, with an adequate molecular weight, mainly depends upon its composition and monomer ratio. For example, the terpolymer $S_{2}$, with an adequate molecular weight, was a better flow improver than $S_{3}$ in almost similar composition conditions. Similarly, the terpolymer $\mathrm{S}_{3}$ and $\mathrm{S}_{2}$, with very different molecular weights and similar composition, show completely different flow behavior. In contrast, $\mathrm{S}_{4}$ and $\mathrm{S}_{5}$, with a rich alkane chain composition, both show the apparent viscosity reduction. The viscosity curve confirms that terpolymer $S_{5}$ exhibited the most considerable reduction of apparent viscosity. An analysis of rheological behavior of a series of terpolymers used as viscosity reducers reveals that, the higher content of DM, the greater the viscosity reduction. Furthermore, suitable long-chain alkanes (MM, DM) can improve the performance of terpolymer, when the content of styrene is higher. The performance of a terpolymer as a flow improver can be explained: (1) long-chain alkyl of terpolymer stretch in the periphery of the new structure, with a large degree of spatial extension, preventing further agglomeration of resin and asphaltene molecules and improve mobility of crude oil; (2) aromatic compounds with a certain rigidity in the terpolymer head capable of interacting with asphaltene aggregates by $\pi-\pi$ stacking and hydrogen-bond formation. Also, the sheet structure of aromatic rings has dispersion and dissolution functions; (3) vinyl acetate is widely used in pour point depressants in the oil industry. Smaller molecules have more penetrating character, to fit into the crude chemical structure, and they also have a certain effect on viscosity reduction. Terpolymers added to the crude oil disperses in asphaltenes and resins, overcoming hydrogen bonds, creating new spaces, and thus reducing the apparent viscosity of heavy crude oil.

\section{Effect of the concentration of terpolymers on apparent viscosity}

Viscosity reducing chemicals' (VRC) efficiencies as a function of terpolymers concentration are shown in Fig. 8. It can be seen that efficiencies grow rapidly for terpolymers $S_{2}$ and $S_{5}$, but it is lower for terpolymer $\mathrm{S}_{4}$ than for terpolymers $\mathrm{S}_{2}$ and $\mathrm{S}_{5}$, which have efficiencies above $30 \%$ at $1 \mathrm{wt} \%$. The efficiency of the terpolymer is higher in the optimal concentration. When it exceeds the optimum additive concentration, the effect of viscosity reduction will be worse. The main reason for the increase in viscosity could be that the higher molecular weight polymer is adsorbed on the resin and asphaltene molecules, ${ }^{10}$ and, a large number of experiments have confirmed this phenomenon. Therefore, optimal concentration of terpolymers should also be concerned in the laboratory experiment.

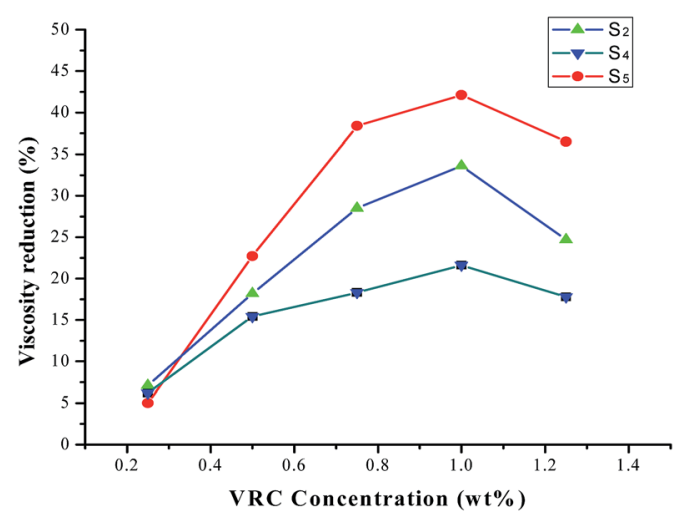

Fig. 8 Viscosity reduction of heavy oil with different VRC concentration at $50{ }^{\circ} \mathrm{C}$. 


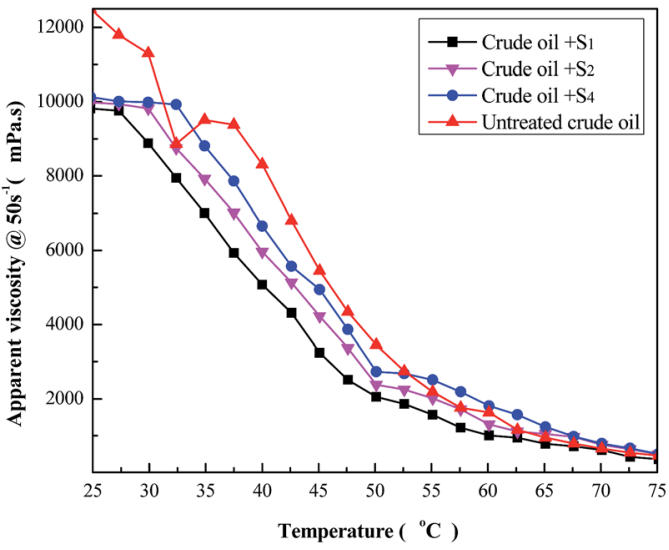

Fig. 9 Temperature effect on the apparent viscosity of the heavy crude oil containing $1 \mathrm{wt} \%$ of terpolymer solution.

\section{E. Effect of formation temperature on apparent viscosity}

Fig. 9 shows the results of both untreated and treated heavy oil viscosity versus temperature (in $25-75{ }^{\circ} \mathrm{C}$ ), in which all samples were examined at a shear rate $(\gamma)$ of $50 \mathrm{~s}^{-1}$. Also, it clearly shows that the addition of the viscosity reducer causes viscosity reduction, being more evident between $30-50{ }^{\circ} \mathrm{C}$. The terpolymer $\mathrm{S}_{5}$ is the best additive for reducing viscosity, sensibly improving the flow. Indeed, crude oil with the $\mathrm{S}_{5}$ agent presents $40.5 \%$ of viscosity reduction at $50{ }^{\circ} \mathrm{C}$. It is possible to compare viscosity variation of the three best terpolymers.

\section{Conclusions}

In this study, SARA analysis shows that the content of asphaltene and resins in the crude oil was up to $27.51 \mathrm{wt} \%$ and 19.03 wt $\%$. These two parts of non-hydrocarbon component are the main aims in the process of reducing the viscosity of heavy oil. The following conclusions can be drawn from this research work:

(1) A series of terpolymers additives (DM-S-VA, MM-S-VA) were successfully designed, synthesized, and evaluated as viscosity reducing chemicals for heavy crude oil from Tahe Oilfield. Terpolymers $\mathrm{S}_{2}$, and $\mathrm{S}_{5}$ show good efficiency as viscosity reducing chemicals and satisfy the requirements of flow improvers. The molecular weight of terpolymers is a problem worthy of attention when comparing the $S_{2}$ and $S_{3}$, which is closely related to the solubility in the heavy crude oil.

(2) The introduction of aromatic compounds (styrene) with a certain rigidity, into the terpolymers, make it capable of interacting with asphaltene aggregates by $\pi-\pi$ stacking and hydrogen-bond formation. It is important to note that suitable long-chain alkyl groups in terpolymers show better advantage, and this efficiency could directly related to the initial components of crude oil. The role of the aromatic compounds and the long-chain alkyl groups could not be neglected, where terpolymers $S_{2}, S_{4}$ and $S_{5}$ have better efficiency than other groups.

(3) The viscosity reducing effect of terpolymers decreased as temperature increased form temperature curve, and temperature is the dominant factor affecting viscosity of crude oil after about $50{ }^{\circ} \mathrm{C}$. However, the higher heat in the pit shaft is helpful in the contact interaction between terpolymers and heavy oil molecules. Therefore, this process can promote the effect of viscosity reduction when the oil is cooled down in lifting and transportation.

(4) The aggregation mechanism of asphaltene and resin is the basis for viscosity reducer, and how the monomers in viscosity reducing chemicals interact with the surfaces to reduce friction and improve flow properties of heavy crude oil in lifting and transportation, are performed in our laboratory.

\section{Acknowledgements}

The research is supported by Sichuan Youth Science \& Technology Foundation (2017JQ0010), National High Technology Research \& Development Program (2016ZX05053), Key Fund Project of Educational Commission of Sichuan Province (16CZ0008), Explorative Project Fund (G201601) of State Key Laboratory of Oil and Gas Reservoir Geology and Exploitation (Southwest Petroleum University), the Major Program of the National Natural Science Foundation of China (51490653) and 973 Program (2013CB228004).

\section{Notes and references}

1 J. Murillo-Hernández, I. García-Cruz, S. López-Ramírez, C. Durán-Valencia, J. M. Domínguez and J. Aburto, Energy Fuels, 2009, 23, 4584.

2 L. V. Castro, E. A. Flores and F. Vázquez, Energy Fuels, 2011, 25, 539.

3 T. E. Chávez-Miyauchi, L. S. Zamudio-Rivera and V. BarbaLópez, Energy Fuels, 2013, 27, 1994.

4 B. Wu and J. Gao, Pet. Sci. Technol., 2010, 28, 1919.

5 J. J. Ge, A. Z. Feng, G. C. Zhang, P. Jiang, H. H. Pei, R. D. Li and X. Fu, Energy Fuels, 2012, 26, 2875.

6 Z. Huang, L. Yang and B. Wang, J. Jilin Inst. Chem. Technol., 2003, 20, 25.

7 H. H. Pei, G. C. Zhang, J. J. Ge, M. G. Tang and Y. F. Zheng, Energy Fuels, 2012, 26, 2911.

8 L. V. Castro and F. Vázquez, Energy Fuels, 2008, 22, 4006.

9 L. V. Castro and F. Vázquez, Energy Fuels, 2009, 23, 1603.

10 M. Cui, C. Li and P. Wen, J. China Univ. Pet., Ed. Nat. Sci., 2013, 37, 161.

11 Y. Peysson, A. Bensakhria, G. Antonini and J. F. Argillier, $S P E$ Prod. Oper., 2007, 22, 135.

12 J. Li, Oilfield Chem., 1987, 4, 146.

13 H. Sun and F. S. Zhang, Fine Spec. Chem., 2005, 13, 16.

14 B. F. Wu and J. B. Guo, Oil Gas Storage Transp., 2003, 22, 6. 15 F. S. Zhang and B. Wang, Oilfield Chem., 2003, 12, 117.

16 A. Bensakhria, Y. Peysson and G. Antonini, Oil Gas Sci. Technol., 2004, 59, 523.

17 D. Chanda, A. Sarmah, A. Borthakur, K. V. Rao, B. Subrahmanyam and H. C. Das, Fuel, 1998, 77, 1163. 